\title{
Anti-Inflammatory Effects of Sosiho-Tang, a Traditional Herbal Formula, on Acute Lung Injury in LPS-Sensitized Mice and -Raw 264.7 Cells
}

\author{
La Yoon Choi $\mathbb{D},{ }^{1}$ Mi Hye Kim $\mathbb{D}^{1},{ }^{1}$ Da-Hwa Jung $\mathbb{D},{ }^{2}$ and Woong Mo Yang $\mathbb{D}^{1}$ \\ ${ }^{1}$ Department of Convergence Korean Medical Science, College of Korean Medicine, Kyung Hee University, \\ Seoul 02447, Republic of Korea \\ ${ }^{2}$ National Development Institute of Korean Medicine, 288 Udeurandeu-gil, Sejong, Janheung-gun 59338, Republic of Korea
}

Correspondence should be addressed to Woong Mo Yang; wmyang@khu.ac.kr

Received 3 December 2020; Revised 21 January 2021; Accepted 29 January 2021; Published 9 February 2021

Academic Editor: Saeideh Saadat

Copyright (C) 2021 La Yoon Choi et al. This is an open access article distributed under the Creative Commons Attribution License, which permits unrestricted use, distribution, and reproduction in any medium, provided the original work is properly cited.

Acute lung injury (ALI) is a series of syndromes with persistent inflammation and abnormally increased vascular permeability. Sosiho-tang (SSHT), a traditional herbal formula consisting of a mixture of seven herbs, has been used to treat allergic reactions and chronic hepatitis disease in East Asia. In this study, we determined whether SSHT has an inhibitory effect against lipopolysaccharide- (LPS-) induced acute lung injury (ALI) in mice. $0.05,0.55$, and $5.55 \mathrm{mg} / \mathrm{kg}$ of SSHT were orally administered to C57BL/6 J mice for 7 days prior to the administration of LPS. After $2 \mathrm{~h}$ of LPS sensitization, lung tissues were collected to confirm the lung histology and ALI-related inflammatory factors. SSHT ameliorated the LPS-induced alveolar hemorrhage, alveolar wall thickening, and the shrinkage of the alveolar spaces in the ALI mice model. Proinflammatory cytokines including IL-6, TNF- $\alpha$, and IFN- $\gamma$ in the lung tissue were significantly regulated in the SSHT-treated groups compared to the LPS only-treated group. Also, increases of IL- 6 and TNF- $\alpha$ and decrease of IFN- $\gamma$ expressions were dose-dependently modulated by SSHT treatment in LPS-induced raw 264.7 cells. Additionally, the translocation of NF- $\kappa$ B into nucleus and phosphorylation of mitogen-activated protein (MAP) kinase were significantly attenuated by the treatment of SSHT in LPS-sensitized ALI mice. SSHT showed antiinflammatory activities by inhibiting proinflammatory cytokines and NF- $\kappa$ B signaling in LPS-induced ALI. This study demonstrates that SSHT has preventive effects on LPS-induced ALI by regulating inflammatory responses as an alternative for treating lung diseases.

\section{Introduction}

Acute lung injury (ALI) is a life-threatening medical complication with a range from 52 to $65 \%$ of mortality rate in patients [1]. ALI is associated with sepsis, traumatic injuries, inhalation, massive blood transfusion, bilateral pulmonary infiltration, and hypoxemia [2]. It is commonly accompanied by systemic inflammatory responses following pulmonary edema, increase of alveolar capillary barrier permeability, and excessive cytokines production in lung [3-5]. In the previous studies, lipopolysaccharide (LPS), component of Gram-negative bacteria, has been known to induce the release of proinflammatory cytokines such as tumor necrosis factor- $\alpha$ (TNF- $\alpha$ ) and interleukin-6 (IL-6), which stimulates alveolar hemorrhage, alveolar wall thickening, and alveolar spaces shrinkage [6, 7].

Clinically, treatment of ALI focuses on counterbalance of inflammatory response by regulating inflammatory/antiinflammatory cytokines production [8]. Some studies have reported that methylprednisolone reduces ventilation, respiratory shock, and mortality rate in ALI patients by improving the systemic inflammatory response [9]. However, the efficacy of methylprednisolone, one of the representative corticosteroids, is controversial, because some studies reported no significant benefit on ALI in clinical trials $[10,11]$. In addition, there were unexpected side effects of corticosteroids such as hyperglycemia, hypertension, and further severe neuronal disorder $[12,13]$. Commonly, inhalation of 
oxygen and restriction of intravenously received fluids are primary treatments for ALI; however, they may lead to pulmonary edema and interstitial pneumonitis due to the increase of pulmonary venous oxygenation caused by hyperoxia $[14,15]$. Novel treatment derived from natural products with no side effects is required to treat ALI.

Sosiho-tang, known as Sho-saiko-to in Japanese and Xiao-Chai-Hu-Tang in Chinese, is an herbal medicine in Korea for medical insurance. Sosiho-tang consists of seven herbs: Bupleurum falcatum Linne $12 \mathrm{~g}$, Scutellaria baicalensis Georgi $8 \mathrm{~g}$, Pinellia ternata Breitenbach $4 \mathrm{~g}$, Panax ginseng C. A. Meyer $4 \mathrm{~g}$, Glycyrrhiza glabra Linn var. glandulifera Regel \& Herder $2 \mathrm{~g}, 3$ of Zingiber officinale Roscoe, and 2 of Ziziphus vulgaris Lamarck var. inermis Bunge. It is widely used for treating allergic diseases, coldrelated symptoms, and chronic liver disease [16-19]. In particular, diseases for which medicine is efficacious of Sosiho-tang include the dyshepatia and hepatosis of chronic liver disorders [20, 21]. In the preclinical studies, Sosiho-tang improved liver inflammation and fibrosis by regulating liver toxicity levels, demonstrating that research of Sosiho-tang is focused on liver disease $[19,22,23]$. Because Sosiho-tang is reported to decrease the production of $\mathrm{T}$ helper 2-type cytokines and chemokine [24], we postulated that Sosihotang has a therapeutic effect on ALI via its anti-inflammatory effects. In the present study, inflammatory effects of Sosihotang against ALI were determined in LPS-sensitized mice and raw 264.7 cells.

\section{Materials and Methods}

2.1. Sosiho-Tang Soft Extract Sample. The sample of Sosihotang used in this study was Jungwoo Pharmacy Sosiho-tang Soft Ext. (SSHT), a prescription-based medicine in Korea. SSHT, a Korean Medicine for national health insurance, was obtained from Jungwoo Pharmacy Co., Ltd. (Lot. no. 702). Briefly, SSHT consists of $750 \mathrm{mg}$ of Bupleurum falcatum Linne, $1.115 \mathrm{~g}$ of Scutellaria baicalensis Georgi, $588 \mathrm{mg}$ of Pinellia ternate Breitenbach, $514 \mathrm{mg}$ of Panax ginseng C. A. Meyer, $246 \mathrm{mg}$ of Glycyrrhiza glabra Linn var. glandulifera Regel \& Herder, $75 \mathrm{mg}$ of Zingiber officinale Roscoe, and $518 \mathrm{mg}$ of Ziziphus vulgaris Lamarck var. inermis Bunge soft extracts based on the general requirements in the Korean Pharmacopoeia. A total of $9 \mathrm{~g}$ of SSHT was dissolved in distilled water with appropriate doses for mice.

2.2. Animal Treatment. Thirty-six males C57BL/6 mice at 5 weeks of age were purchased from Raon Bio Inc. (Yongin, Korea). Mice were housed under controlled conditions (at $24 \pm 2^{\circ} \mathrm{C}$, relative humidity of $50-80 \%$, and $12 \mathrm{~h}$ light/dark cycle). After 1-week acclimation, mice were randomly divided into six groups with 6 per group: CTR (nontreated group as a normal control), LPS (LPS-sensitized group as a negative control), DEX (LPS-sensitized and DEX-treated group as a positive control), S0.05 (LPS-sensitized and SSHT $0.05 \mathrm{~g} / \mathrm{kg}$-treated group), S0.55 (LPS-sensitized and SSHT $0.55 \mathrm{~g} / \mathrm{kg}$-treated group), and S5.55 (LPS-sensitized and SSHT $5.55 \mathrm{~g} / \mathrm{kg}$-treated group). $7 \mathrm{mg} / \mathrm{kg}$ of dexamethasone
(DEX) and SSHT were orally preadministrated for 1 week, followed by intraperitoneal injection of $10 \mathrm{mg} / \mathrm{kg}$ LPS. The SSHT that was used for the human being $9 \mathrm{~g} / 60 \mathrm{~kg} /$ day was converted by using the human equivalent dose (HED) equation used for mice into $5.55 \mathrm{~g} / \mathrm{kg}$. There was no toxicity to mice during sample administration of SSHT $5.55 \mathrm{~g} / \mathrm{kg}$. Following LPS sensitization for $2 \mathrm{~h}$, blood samples were collected by cardiac puncture. Lung tissues were collected at $10 \%$ neutralized formalin solution. All experiments were approved by the Committee on Care and Use of Laboratory Animals of Kyung Hee University (KHUASP(SE)-18-078; Seoul, Korea).

2.3. Histological Analysis. The right inferior lobe of lung was fixed at $10 \%$ neutralized formalin for $24 \mathrm{~h}$. The lung tissues were dehydrated and embedded in paraffin for $24 \mathrm{~h}$. The paraffin blocks were cross cut into $4 \mu \mathrm{m}$ thickness and mounted on slides. These slides were stained with hematoxylin and eosin solution. The stained slides were photographed by digital microscope at a magnification of $200 \times$ and $400 \times$. The blind test for ALI score was determined as 0 to 5 grades: 0 , no injury and appears normal; 1 , minimal (injury up to $25 \%$ of the field); 2 , mild (injury between 25 and $50 \%$ of the field); 3 , moderate (injury between 50 and $75 \%$ of the field); and 4 , severe ( $>75 \%$, diffuse injury). Tissue sections were examined by a pathologist blinded to the experiment.

2.4. Cell Treatment. Raw 264.7 cells were grown in Dulbecco's modified Eagle's medium (DMEM) (Gibco; Thermo Fisher Scientific, Inc., Waltham, MA, USA) supplemented with $10 \% \mathrm{v} / \mathrm{v}$ fetal bovine serum (Gibco), $2 \mathrm{mM}$ glutamine, $100 \mathrm{IU} / \mathrm{ml}$ penicillin, and $100 \mu \mathrm{g} / \mathrm{mL}$ streptomycin (Gibco). Cells were grown at $37^{\circ} \mathrm{C}$ in an atmosphere containing $5 \%$ $\mathrm{CO}_{2}$ of $95 \%$ humidity. Cells were seeded in 6-well plates and treated with $1,10,100,250,500$, and $1000 \mu \mathrm{g} / \mathrm{mL}$ of SSHT in the presence of LPS $1 \mu \mathrm{g} / \mathrm{mL}$ for $24 \mathrm{~h}$. DEX was treated at the $1 \mu \mathrm{g} / \mathrm{mL}$ concentration to raw 264.7 cells for $24 \mathrm{~h}$.

2.5. Preparations of Protein Extracts. Whole left lobe of lung tissues containing the left-upper lobe and the lower lobe was homogenized using a radioimmunoprecipitation assay (RIPA) lysis buffer (50 mm Tris-HCl, pH 7.4, $1 \%$ Nonidet $\mathrm{P}-40,0.5 \%$ sodium deoxycholate, and $150 \mathrm{mM} \mathrm{NaCl}$ ) containing protease inhibitor cocktail (Roche Diagnostics, Indianapolis, IN, USA) for extracts of whole proteins. The lysed proteins were centrifuged at $15,928 \mathrm{~g}$ for $10 \mathrm{~min}$ at $4^{\circ} \mathrm{C}$ and collected supernatant was used to determine mitogenactivated protein (MAP) Kinase, ERK1/2, SAPK/JNK, and p38. To extract cytoplasmic proteins, frozen lung tissues were homogenized with cytoplasmic buffer (10 mM HEPES, pH 7.9, $20 \mathrm{mM} \mathrm{KCl}, 0.1 \mathrm{mM}$ EDTA, $0.1 \mathrm{mM}$ EGTA, $1 \mathrm{mM}$ DTT, $0.15 \%$ Nonidet P-40, $50 \mathrm{mM} \beta$-glycerophosphate, $10 \mathrm{mM} \mathrm{NaF}$, and $5 \mathrm{mM} \mathrm{Na} 3 \mathrm{VO} 4)$ containing the protease inhibitor cocktail and centrifuged at $24 \mathrm{~g}$ for $5 \mathrm{~min}$. The supernatants obtained from the homogenate are used to analyze $\mathrm{I} \kappa \mathrm{B}-\alpha$ and phospho-I $\kappa \mathrm{B}-\alpha$. For nuclear protein extraction, a nuclear lysis buffer (20 mM HEPES, pH 7.9, 
$400 \mathrm{mM} \mathrm{NaCl}, 1 \mathrm{mM}$ EDTA, 1 mM EGTA, 1 mM DTT, 0.5\% Nonidet P-40, $50 \mathrm{mM} \beta$-glycerophosphate, $10 \mathrm{mM} \mathrm{NaF}$, and $5 \mathrm{mM}$ Na3VO4) containing a protease inhibitor cocktail was added to the pellet. Nuclear protein was centrifuged at $15,928 \mathrm{~g}$ for $10 \mathrm{~min}$ to detect NF- $\kappa \mathrm{B}$.

2.6. Western Blotting Analysis. The amount of proteins was quantified using the Bradford protein assay. Protein samples (20 $\mu \mathrm{g} /$ lane) were separated into $10 \%$ SDS-PAGE gel and transferred to polyvinylidene fluoride (PVDF) membranes. The membrane was blocked for $1 \mathrm{~h}$ in TBS containing $0.1 \%$ Tween (TBS-T) and 5\% bovine serum albumin. The membrane was incubated overnight at $4^{\circ} \mathrm{C}$ with primary antibodies. The following antibodies were used in this study: $\beta$-actin (1:1000; cat. no. sc-47778; Santa Cruz Biotechnology), ERK1/2 (1:1000; cat. no. 4695S; Cell Signaling Technology), phospho-ERK1/2 (1:1000; cat. no. 4370S; Cell Signaling Technology), SAPK/JNK (1:1000; cat. no. 9252S; Cell Signaling Technology), phospho-SAPK/JNK (1:1000; cat. no. sc-293138; Santa Cruz Biotechnology), p38 (1:1000; cat. no. 9212; Cell Signaling Technology), phospho-p38 (1: 1000; cat. no. sc-166182; Santa Cruz Biotechnology), NF- $\kappa \mathrm{B}$ (1:1000; cat. no. 3034S; Cell Signaling Technology), I $\kappa \mathrm{B}-\alpha$ (1: 1000; cat. no. sc-1643; Santa Cruz Biotechnology), and phospho-I $\kappa$ B- $\alpha$ (1:1000; cat. no. sc-8404; Santa Cruz Biotechnology). Anti-mouse IgG (1:3000; cat. no. sc-516102; Santa Cruz Biotechnology) and anti-rabbit IgG (1:4000; cat. no. sc-2357; Santa Cruz Biotechnology) secondary antibodies were incubated room temperature for $1 \mathrm{~h}$. The blots were visualized by Davinch-Chemi (cat no. CAS400 MF; Davinch-K, Seoul, Korea) with enhanced chemiluminescence kit (cat. no. ABC-3001; AbClon, Seoul, Korea).

2.7. Reverse Transcription Polymerase Chain Reaction (RT$P C R)$ Analysis. For RNA extraction, the lung tissues and raw 264.7 cells were homogenized in TRIzol reagent (Invitrogen Corp., Carlsbad, CA, USA), according to the manufacturer's instructions. The optical density was read at a wavelength of $260 \mathrm{~nm}$ to quantify RNA. To synthesize complementary DNA, Maxime RT PreMix (Invitrogen) was mixed with $1 \mu \mathrm{g}$ RNA at $45^{\circ} \mathrm{C}$ for 1 hour and incubated at $95^{\circ} \mathrm{C}$ for $5 \mathrm{~min}$. PCR was performed using Maxime PCR PreMix (Invitrogen) and synthesized cDNA template. The sequence of the primers used was as shown in Table 1. The amplification conditions were $94^{\circ} \mathrm{C}$ for $30 \mathrm{sec}$, followed by 40 cycles of $94^{\circ} \mathrm{C}$ for $1 \mathrm{~min}$, range from 58 to $70^{\circ} \mathrm{C}$ for $30 \mathrm{sec}, 72^{\circ} \mathrm{C}$ for $1 \mathrm{~min}$ and final extension at $72^{\circ} \mathrm{C}$ for $5 \mathrm{~min}$. The relative expressions of gene were calculated and normalized to GAPDH and analyzed by Image J software.

2.8. Statistical Analysis. Significance was determined by oneway analysis of variance (ANOVA) and Tukey's multiple comparison tests. In all analyses, $p<0.05$ was taken to indicate statistical significance.

\section{Results}

3.1. Effects of SSHT on the Histological Analysis of Lung Tissue. Histological analysis was conducted to evaluate whether SSHT recovers LPS-induced change of lung structure. Compared to the structure of lung tissues in normal group, the LPS group led to alveolar hemorrhage, alveolar wall thickening, and alveolar spaces shrinkage. In contrast, SSHT treatment relieved alveolar wall thickness and alveolar spaces shrinkage similar to normal group (Figure 1(a)). The ALI score by LPS sensitization was 3.5 times higher than nontreated CTR group $(p<0.05)$. SSHT treatment at all concentrations $(0.05,0.55$, and $5.55 \mathrm{~g} / \mathrm{kg})$ significantly decreased the histology scores by $34.5 \%, 46.2 \%$, and $42.2 \%(p<0.05)$, respectively, while DEX treatment showed $51.8 \%$ reduction $(p<0.05)$ of ALI score in LPSsensitized mice (Figure 1(b)).

\subsection{Effects of SSHT on Expression of Inflammatory Cytokines} IL-6, TNF- $\alpha$, and IFN- $\gamma$ in Lung Tissues and Raw 264.7 Cells. To examine whether SSHT treatment inhibits LPS-induced inflammation in ALI model, proinflammatory cytokines IL6, TNF- $\alpha$, and interferon- $\gamma$ (IFN- $\gamma$ ) in lung tissue was assessed by RT-PCR. Expression of IL- 6 was increased 3.18 times $(p<0.05)$ in LPS-treated group compared to the normal group. SSHT treatment at the concentrations of 0.55 and $5.55 \mathrm{~g} / \mathrm{kg}$ decreased expression of IL-6 to $34.1 \%$ and $55.4 \%$ of LPS-treated group, respectively $(p<0.05)$. The levels of TNF- $\alpha$ increased 3.56 times of LPS-treated group than that in the normal group $(p<0.05)$. Expression of TNF$\alpha$ was decreased $58.5 \%$ in treated with $5.55 \mathrm{~g} / \mathrm{kg}$ of SSHT $(p<0.05)$. In contrast with the other cytokine expression levels, expression of IFN- $\gamma$ was 0.57 times decreased in LPStreated group compared with the nontreated CTR group $(p<0.05)$. SSHT treatment with $5.55 \mathrm{~g} / \mathrm{kg}$ increased the expression of IFN- $\gamma \quad 35.94 \%$ compared to LPS group (Figure 2(a)) $(p<0.05)$.

Additionally, the expressions of IL- 6 and TNF- $\alpha$ in LPSsensitized raw 264.7 cells were 2.8 and 3.0 times increased compared to nontreated cells $(p<0.05)$, while LPS significantly decreased the mRNA level of IFN $-\gamma$ in raw 264.7 cells $(p<0.05)$. In the SSHT-treated cells in the presence of LPS, the expressions of IL- 6 and TNF- $\alpha$ were markedly decreased. 500 and $1000 \mu \mathrm{g} / \mathrm{mL}$ of SSHT significantly inhibited the IL-6 levels, while 250,500 , and $1000 \mu \mathrm{g} / \mathrm{mL}$ of SSHT significantly reduced the TNF- $\alpha$ levels, respectively $(p<0.05)$. Moreover, $1000 \mu \mathrm{g} / \mathrm{mL}$ of SSHT significantly increased the IFN- $\gamma$ expression in LPS-sensitized raw 264.7 cells (Figure 2(b)) $(p<0.05)$.

3.3. Effects of SSHT on NF- $\kappa B$ Translocation and I $\kappa B-\alpha$ Phosphorylation in Lung Tissue. I $\kappa \mathrm{B}-\alpha / \mathrm{NF}-\kappa \mathrm{B}$ pathway is a key regulator of inflammation and highly activated in ALI, while LPS treatment induced the increases of 1.24 times on phosphorylated $\mathrm{I} \kappa \mathrm{B}-\alpha$ and 1.66 times on translocated NF$\kappa \mathrm{B}$, respectively $(p<0.05)$. I $\kappa \mathrm{B}-\alpha$ phosphorylation was reduced $18.6 \%$ and $24.3 \%$ by 0.55 and $5.55 \mathrm{~g} / \mathrm{kg}$ of SSHT treatment, respectively (Figure 3) $(p<0.05)$. Moreover, 
TABLE 1: Sequence of reverse transcription PCR primers.

\begin{tabular}{lcc}
\hline Target gene & $5^{\prime} \longrightarrow 3^{\prime}$ forward primer & $5^{\prime} \longrightarrow 3^{\prime}$ reverse primer \\
\hline IL-6 & CGGAGAGGAGACTTCACAGAGGA & GGAGAGCATTGGAAATTGGGG \\
TNF- $\alpha$ & CCTGTAGCCCACGTCGTAGC & TTGACCTCAGCGCTGAGTTG \\
IFN- $\gamma$ & AGCGGCTGACTGAACTCAGATTGTAG & GTCACAGTTTTCAGCTGTATAGGG \\
GAPDH & GGCATGGACTGTGGTCATGA & TTCACCACCATGGAGAAGGC \\
\hline
\end{tabular}

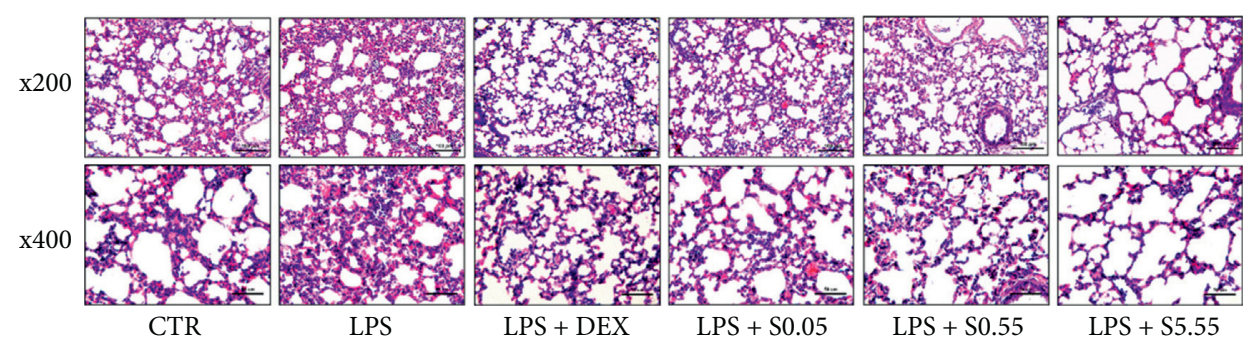

(a)

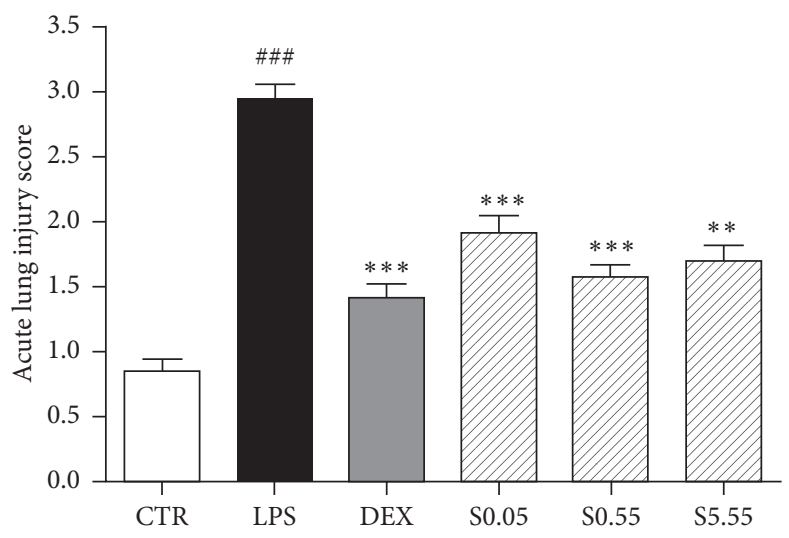

(b)

FIGURE 1: Histological changes of lung tissues indicated by hematoxylin and eosin staining. Representative images of lung tissues (a) and ALI score (b). The sections were stained with hematoxylin and eosin (H\&E). Original magnifications were $200 \times$ and $400 \times$. CTR: normal control group; LPS: LPS-sensitized ALI group; DEX: DEX-treated and LPS-sensitized group; S0.05: $0.05 \mathrm{~g} / \mathrm{kg}$ SSHT-treated and LPS-sensitized group; S0.55: $0.55 \mathrm{~g} / \mathrm{kg}$ SSHT-treated and LPS-sensitized group; and S5.55: $5.55 \mathrm{~g} / \mathrm{kg}$ SSHT-treated and LPS-sensitized group. Results are presented as mean \pm S.E.M. ${ }^{\# \# \#} p<0.001$ compared with CTR group; ${ }^{* * *} p<0.001$ and ${ }^{* *} p<0.01$ compared with the LPS group.

expression of nuclear NF- $\kappa \mathrm{B}$ was also decreased $63.5 \%$, $67.9 \%$, and $88.9 \%$ by SSHT treatment $(p<0.05)$.

\subsection{Effects of SSHT on Expression of MAP Kinase in Lung} Tissue. LPS-induced 1.36 times increase of ERK phosphorylation in lung tissues of mice $(p<0.05)$. Administration of SSHT at all concentrations $(0.05,0.55$, and $5.55 \mathrm{~g} /$ $\mathrm{kg}$ ) had significantly dose-dependently decreased the ERK phosphorylation by $13 \%, 26.4 \%$, and $56.8 \% \quad(p<0.05)$. Phosphorylation of JNK was significantly increased by 2.65 times in LPS-treated group compared with the CTR group $(p<0.05)$, whereas 0.55 and $5.55 \mathrm{~g} / \mathrm{kg}$ of SSHT treatment markedly reduced LPS-induced phosphorylated JNK by $33.7 \%$ and $41 \%(p<0.05)$. In LPS-sensitized mice, phosphorylation of p38 was 1.12 times increased in comparison with normal mice $(p<0.05)$. SSHT $5.55 \mathrm{~g} / \mathrm{kg}$-treated group showed a significant $15.7 \%$ reduction of p38 phosphorylation $(p<0.05)$ (Figure 4$)$.

\section{Discussion}

New finding of efficacy of medicine would be helpful to expand its medical indication as a prescription for health insurance. Recommended daily intake dose of SSHT to human is $9 \mathrm{~g} / \mathrm{day} / 60 \mathrm{~kg}$, converted to $5.55 \mathrm{~g} / \mathrm{kg}$ of SSHT in mice. In this study, $0.05,0.55$, and $5.55 \mathrm{~g} / \mathrm{kg}$ of SSHT were administered to LPS-induced ALI mice. LPS causes histological changes including alveolar hemorrhage, shrinkage of alveolar spaces, and alveolar wall thickening [25]. Those symptoms can be prevented by treatment with SSHT at a concentration of $5.55 \mathrm{~g} / \mathrm{kg}$.

B. falcatum Linne polysaccharides, a major herb of SSHT, suppressed LPS-induced proinflammatory cytokines production including IL- 6 , IL- $1 \beta$, IFN- $\beta$, and TNF- $\alpha$ in peritoneal macrophages of mice [26]. Additionally, baicalin derived from $S$. baicalensis Georgi consisting of SSHT has been studied to decrease TNF- $\alpha$ and IL-1 $\beta$ levels in 

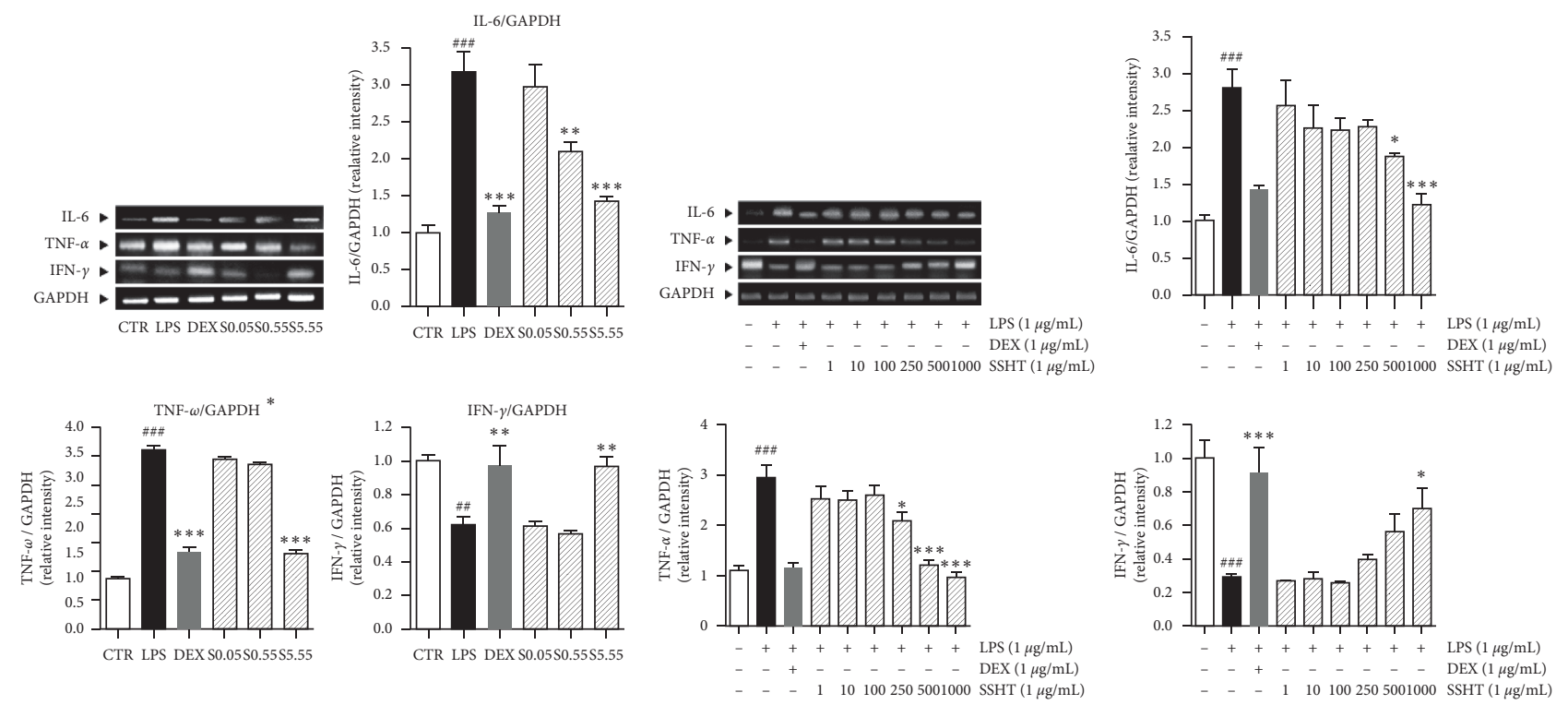

(a)

(b)

FIGURE 2: Expressions of cytokines in lung tissues (a) and raw 264.7 cells (b). CTR: normal control group; LPS: LPS-sensitized ALI group; DEX: DEX-treated and LPS-sensitized group; S0.05: $0.05 \mathrm{~g} / \mathrm{kg}$ SSHT-treated and LPS-sensitized group; S0.55: $0.55 \mathrm{~g} / \mathrm{kg}$ SSHT-treated and LPS-sensitized group; and S5.55: $5.55 \mathrm{~g} / \mathrm{kg}$ SSHT-treated and LPS-sensitized group. Results are presented as mean \pm S.E.M. \#\#\# $p<0.001$ and ${ }^{\# \#} p<0.01$ compared with CTR group and nontreated cells; ${ }^{* * *} p<0.001,{ }^{* *} p<0.01$, and ${ }^{*} p<0.05$ compared with the LPS group and LPS-sensitized cells.

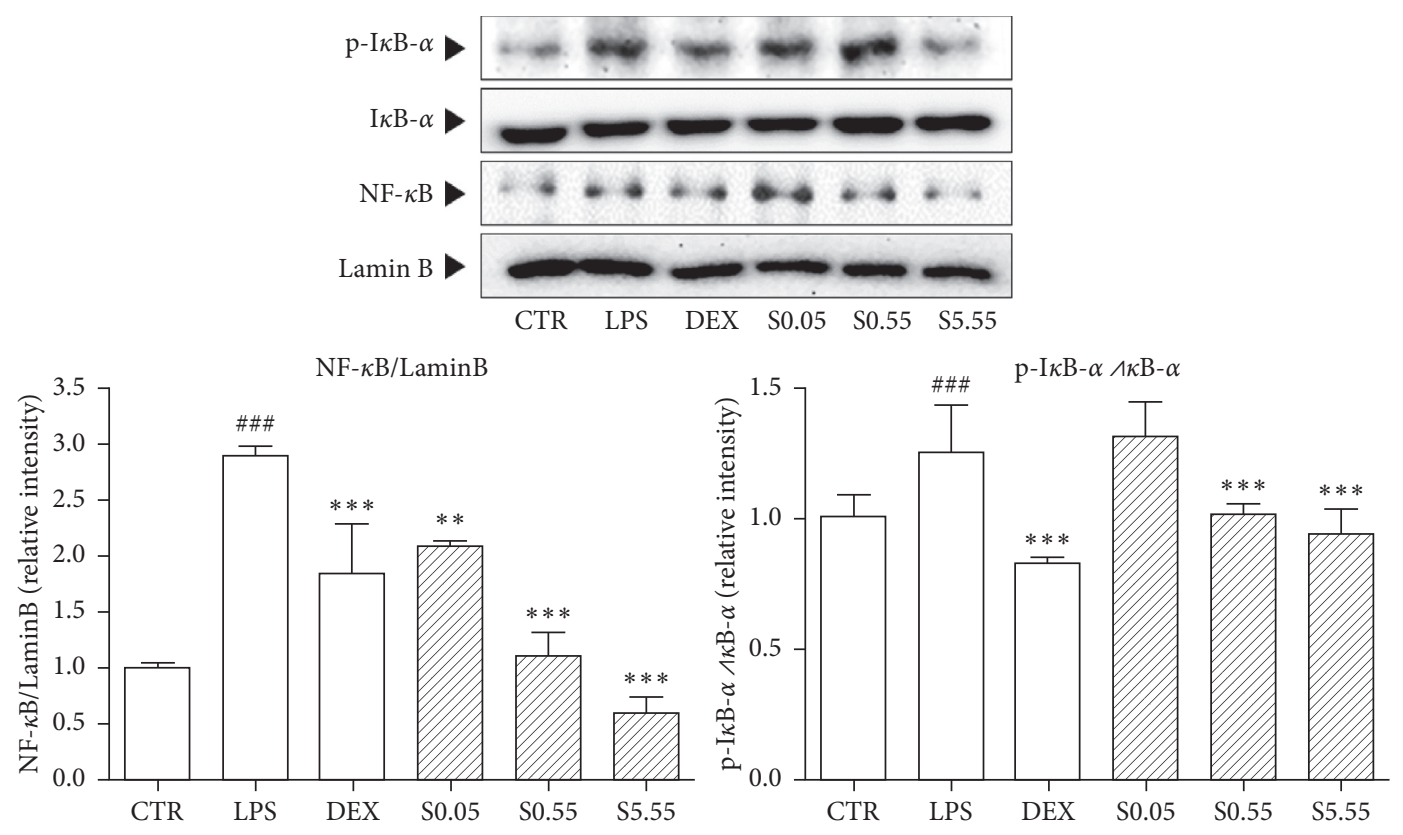

FiguRE 3: Expression of nuclear NF- $\kappa$ B and cytoplasmic I $\kappa$ B- $\alpha$ of lung tissues indicated by western blot analysis. CTR: normal control group; LPS: LPS-sensitized ALI group; DEX: DEX-treated and LPS-sensitized group; S0.05: $0.05 \mathrm{~g} / \mathrm{kg}$ SSHT-treated and LPS-sensitized group; S0.55: $0.55 \mathrm{~g} / \mathrm{kg}$ SSHT-treated and LPS-sensitized group; and S5.55: $5.55 \mathrm{~g} / \mathrm{kg}$ SSHT-treated and LPS-sensitized group. Results are presented as mean \pm S.E.M. ${ }^{\# \# \#} p<0.001$ compared with the CTR group; ${ }^{* * *} p<0.001$ and ${ }^{* *} p<0.01$ compared with the LPS group.

bronchoalveolar lavage fluids of LPS-induced ALI mice [27]. Total saponin from Ginseng as another major herb of SSHT was reported to inhibit LPS-induced increase of serum TNF$\alpha$ level [28]. Based on the previous evidence, we anticipated that SSHT has inhibitory effects against ALI by regulating proinflammatory cytokines. In particular, lung proinflammatory cytokine expressions such as IL-6, TNF- $\alpha$, and IFN- $\gamma$ in ALI model were investigated to find the underlying 

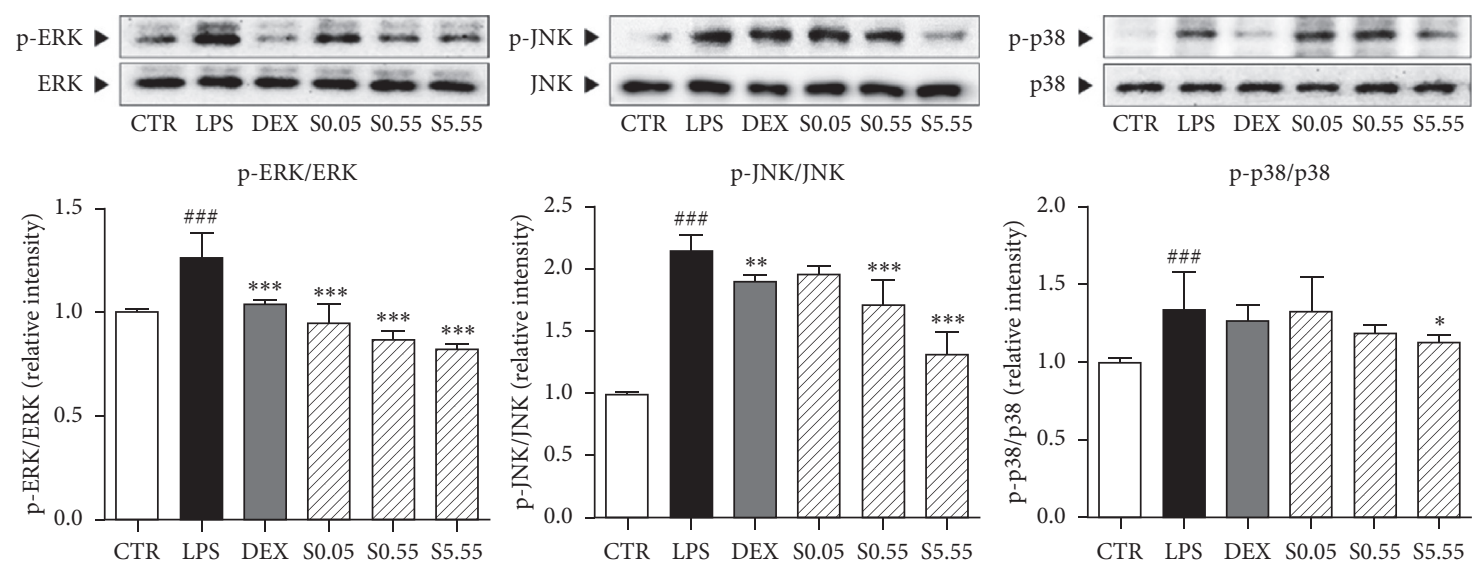

FIgURE 4: Expressions of MAP kinase of lung tissues indicated by western blot analysis. CTR: normal control group; LPS: LPS-sensitized ALI group; DEX: DEX-treated and LPS-sensitized group; S0.05: $0.05 \mathrm{~g} / \mathrm{kg} \mathrm{SSHT-treated} \mathrm{and} \mathrm{LPS-sensitized} \mathrm{group;} \mathrm{S0.55:} \mathrm{0.55} \mathrm{g/kg} \mathrm{SSHT-treated}$ and LPS-sensitized group; and S5.55: $5.55 \mathrm{~g} / \mathrm{kg}$ SSHT-treated and LPS-sensitized group. Results are presented as mean \pm S.E.M. ${ }^{\# \# \#} p<0.001$ compared with the CTR group; ${ }^{* * *} p<0.001,{ }^{* *} p<0.01$, and ${ }^{*} p<0.05$ compared with the LPS group.

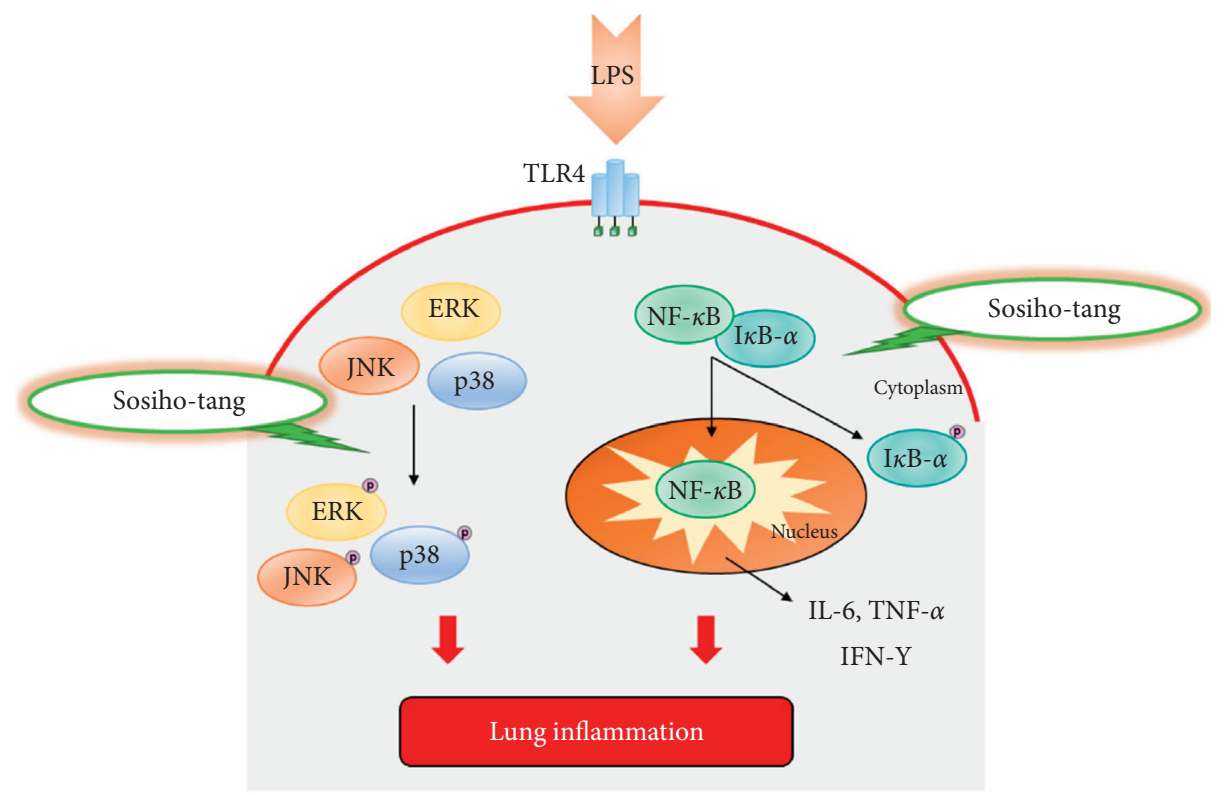

FIGURE 5: Schematic diagram of potential action of SSHT on lung inflammation. SSHT appears to regulate the IL-6, TNF- $\alpha$, and IFN- $\gamma$, following the inhibition of NF- $\kappa \mathrm{B}$ and MAP kinases expressions. These actions inhibit the LPS-induced lung inflammation in ALI.

mechanism of SSHT on the recovery of alveolar wall thickening. Proinflammatory cytokines such as IL-6 and TNF- $\alpha$ are considered key components of the acute inflammatory response [29-31]. Some studies have shown that TNF- $\alpha$ produced by initiating inflammatory response in macrophages undergo to activate NF- $\kappa$ B pathway and MAP kinase [32]. IL-6 is a multifunctional cytokine produced by monocytes and macrophages in the LPS-induced immune response [33]. IFN- $\gamma$ as a primary activator by stimulating innate and adaptive immunity clears intracellular pathogens and produces enzymes to inhibit viral infections $[34,35]$. IL6 and TNF- $\alpha$ mRNA levels in the lung tissues and raw 264.7 cells were increased by exposure of LPS and significantly decreased by the pretreatment or cotreatment with SSHT. Those results demonstrate that SSHT might regulate the counterbalance of inflammatory responses by downregulating IL- 6 and TNF- $\alpha$ and upregulating IFN- $\gamma$.

$\mathrm{NF}-\kappa \mathrm{B}$ is translocated from the cytoplasm to the nucleus by inflammatory cytokines such as IL-6 and TNF- $\alpha$ [36-40]. The nuclear translocation of $\mathrm{NF}-\kappa \mathrm{B}$ is regulated by $\mathrm{I} \kappa \mathrm{B}-\alpha$ proteolytic degradation [41]. Additionally, MAP kinases including ERK12, SAPK/JNK, and p38 are associated with the production of cytokines in the inflammatory response [42]. Inhibition of NF- $\kappa$ B and MAP kinases in LPS-sensitized lung tissues could ameliorate ALI [43]. The expression of NF- $\kappa \mathrm{B}$ and the phosphorylation of $\mathrm{I} \kappa \mathrm{B}-\alpha$ in LPS-sensitized lung tissue were increased, but they were markedly decreased in the SSHT-treated mice. SSHT also significantly reduced the phosphorylation of ERK1/2, SAPK/JNK, and p38 in the lungs. In addition to the results from IL-6 and 
TNF- $\alpha$, SSHT attenuated the activation of MAP kinase and NF- $\kappa$ B by inhibition of inflammatory cytokines such as IL- 6 and TNF- $\alpha$ (Figure 5).

\section{Conclusion}

In conclusion, SSHT alleviated the inflammatory IL-6 and TNF- $\alpha$ production, following the decreases of transcription factors including NF- $\kappa \mathrm{B}$ and MAP kinases. Inhibition of inflammatory responses by SSHT in lung would be helpful to ameliorate LPS-induced ALI. Taken together, SSHT might be beneficial for treating ALI. Since the administration of $5.55 \mathrm{~g} / \mathrm{kg}$ of SSHT to mice is converted to daily intake $9 \mathrm{~g} /$ day/60 kg dose for human, Jungwoo Pharmacy Sosihotang Soft Ext. is applicable for treating lung inflammation. Optimal dosage range of SSHT might be $9 \mathrm{~g} /$ day $/ 60 \mathrm{~kg}$, a daily intake dose for human in present. Further studies regarding the maximal efficacy and toxicity of SSHT are needed.

\section{Abbreviations}

ALI: Acute lung injury

HED: Human equivalent dose

IFN- $\gamma$ : Interferon- $\gamma$

IL: Interleukin

LPS: Lipopolysaccharide

MAP: Mitogen-activated protein

SSHT: Sosiho-tang

TNF- $\alpha$ : Tumor necrosis factor- $\alpha$.

\section{Data Availability}

The data used to support the findings of this study are available from the corresponding author upon reasonable request.

\section{Conflicts of Interest}

The authors declare that they have no conflicts of interest regarding the publication of this paper.

\section{Acknowledgments}

This work was supported by a grant of the National Development Institute of Korean Medicine (NIKOM) funded by the Korean Ministry of Health and Welfare (MOHW), Republic of Korea.

\section{References}

[1] A. Dulu, S. M. Pastores, B. Park, E. Riedel, V. Rusch, and N. A. Halpern, "Prevalence and mortality of acute lung injury and ARDS after lung resection," Chest, vol. 130, no. 1, pp. 73-78, 2006.

[2] D. Parekh, R. C. Dancer, and D. R. Thickett, "Acute lung injury," Clinical Medicine, vol. 11, no. 6, pp. 615-618, 2011.

[3] L. Fan, Y. Fan, L. Liu et al., "Chelerythrine attenuates the inflammation of lipopolysaccharide-induced acute lung inflammation through NF-kappaB signaling pathway mediated by Nrf2," Frontiers in Pharmacology, vol. 9, p. 1047, 2018.
[4] L.-M. Zhang, J. Zhang, Y. Zhang et al., "Interleukin-18 binding protein attenuates lipopolysaccharide-induced acute lung injury in mice via suppression NF- $\kappa \mathrm{B}$ and activation Nrf2 pathway," Biochemical and Biophysical Research Communications, vol. 505, no. 3, pp. 837-842, 2018.

[5] G.-F. Zhu, H.-J. Guo, Y. Huang, C.-T. Wu, and X.-F. Zhang, "Eriodictyol, a plant flavonoid, attenuates LPS-induced acute lung injury through its antioxidative and anti-inflammatory activity," Experimental and Therapeutic Medicine, vol. 10, no. 6, pp. 2259-2266, 2015.

[6] Y. Luo, X. X. Pang, A. R. Ansari et al., "Visfatin exerts immunotherapeutic effects in lipopolysaccharide-induced acute lung injury in murine model," Inflammation, vol. 43, no. 1, pp. 109-122, 2020.

[7] S. A. Lee, S. H. Lee, J. Y. Kim, and W. S. Lee, "Effects of glycyrrhizin on lipopolysaccharide-induced acute lung injury in a mouse model," Journal of Thoracic Disease, vol. 11, no. 4, pp. 1287-1302, 2019.

[8] R. B. Goodman, J. Pugin, J. S. Lee, and M. A. Matthay, "Cytokine-mediated inflammation in acute lung injury," Cytokine and Growth Factor Reviews, vol. 14, no. 6, pp. 523-535, 2003.

[9] Z. Zhang, L. Chen, and H. Ni, "The effectiveness of Corticosteroids on mortality in patients with acute respiratory distress syndrome or acute lung injury: a secondary analysis," Sci Rep, vol. 5, Article ID 17654, 2015.

[10] E. N. Deal, J. M. Hollands, G. E. Schramm, and S. T. Micek, "Role of corticosteroids in the management of acute respiratory distress syndrome," Clinical Therapeutics, vol. 30, no. 5, pp. 787-799, 2008.

[11] D. Mokra, P. Mikolka, P. Kosutova, and J. Mokry, "Corticosteroids in acute lung injury: the dilemma continues," International Journal of Molecular Sciences, vol. 20, p. 19, 2019.

[12] C. S. Calfee and M. A. Matthay, "Nonventilatory treatments for acute lung injury and ARDS," Chest, vol. 131, no. 3, pp. 913-920, 2007.

[13] G. R. Sethi and K. K. Singhal, "Pulmonary diseases and corticosteroids," The Indian Journal of Pediatrics, vol. 75, no. 10, pp. 1045-1056, 2008.

[14] M. J. Lan and X. D. He, "Prone positioning ventilation for treatment of acute lung injury and acute respiratory distress syndrome," Chinese Journal of Traumatology = Zhonghua Chuang Shang Za Zhi, vol. 12, no. 4, pp. 238-242, 2009.

[15] W. J. Mach, A. R. Thimmesch, J. T. Pierce, and J. D. Pierce, "Consequences of hyperoxia and the toxicity of oxygen in the lung," Nursing Research and Practice, vol. 2011, Article ID 260482, 7 pages, 2011.

[16] K. Kayano, I. Sakaida, K. Uchida, and K. Okita, "Inhibitory effects of the herbal medicine Sho-saiko-to (TJ-9) on cell proliferation and procollagen gene expressions in cultured rat hepatic stellate cells," Journal of Hepatology, vol. 29, no. 4, pp. 642-649, 1998.

[17] H. M. Kim, Y. Y. Kim, H. Y. Jang, S. J. Moon, and N. H. An, "Action of sosiho-tang on systemic and local anaphyls by anal administration," Immunopharmacology and Immunotoxicology, vol. 21, no. 3, pp. 635-643, 1999.

[18] Y. C. Oh, W. K. Cho, Y. H. Jeong et al., "Anti-inflammatory effect of Sosihotang via inhibition of nuclear factor-kappaB and mitogen-activated protein kinases signaling pathways in lipopolysaccharide-stimulated RAW 264.7 macrophage cells," Food and Chemical Toxicology, vol. 53, pp. 343-351, 2012.

[19] N. Ohtake, R. Suzuki, H. Daikuhara et al., "Modulation of lung local immune responses by oral administration of a 
herbal medicine Sho-saiko-to," International Journal of Immunopharmacology, vol. 22, no. 6, pp. 419-430, 2000.

[20] M. Nose, K. Terawaki, N. Iwahashi, K. Oguri, and Y. Ogihara, "Comparative study of the high molecular mass fraction and low molecular mass fraction of Sho-saiko-to in a murine immunologically induced liver injury model," Biological and Pharmaceutical Bulletin, vol. 25, no. 1, pp. 64-67, 1997.

[21] M. Kusunose, B. Qiu, T. Cui et al., "Effect of Sho-saiko-to extract on hepatic inflammation and fibrosis in dimethylnitrosamine induced liver injury rats," Biological and Pharmaceutical Bulletin, vol. 25, no. 11, pp. 1417-1421, 2002.

[22] N. Ohtake, Y. Nakai, M. Yamamoto et al., "The herbal medicine Shosaiko-to exerts different modulating effects on lung local immune responses among mouse strains," International Immunopharmacology, vol. 2, no. 2-3, pp. 357-366, 2002.

[23] S. Sakaguchi, S. Furusawa, and Y. Iizuka, "Preventive effects of a traditional Chinese medicine (Sho-saiko-to) on septic shock symptoms; approached from heme metabolic disorders in endotoxemia," Biological and Pharmaceutical Bulletin, vol. 28, no. 1, pp. 165-168, 2005.

[24] W. Y. Jeon, H. K. Shin, I. S. Shin, S. K. Kim, and M. Y. Lee, "Soshiho-tang water extract inhibits ovalbumin-induced airway inflammation via the regulation of heme oxygenase-1," BMC Complementary and Alternative Medicine, vol. 15, p. 329, 2015.

[25] Y. Li, G. Chi, B. Shen, Y. Tian, and H. Feng, "Isorhamnetin ameliorates LPS-induced inflammatory response through downregulation of NF-kappaB signaling," Inflammation, vol. 39, no. 4, pp. 1291-1301, 2018.

[26] J. Wu, Y. Y. Zhang, L. Guo, H. Li, and D. F. Chen, "Bupleurum polysaccharides attenuates lipopolysaccharide-induced inflammation via modulating Toll-like receptor 4 signaling," PLoS One, vol. 8, no. 10, Article ID e78051, 2013.

[27] Y. Long, Y. Xiang, S. Liu et al., "Baicalin liposome alleviates lipopolysaccharide-induced acute lung injury in mice via inhibiting TLR4/JNK/ERK/NF-kappaB pathway," Mediators of Inflammation, vol. 2020, Article ID 8414062, 11 pages, 2020.

[28] K. M. Kim, H. J. Kim, J. Ryu, and D. H. Sohn, "Ginseng saponin prevents the LPS-induced TNF-Ît production in mice," Journal of Ginseng Research, vol. 24, no. 2, pp. 79-82, 2013.

[29] K. V. Ramana, A. A. Fadl, R. Tammali, A. B. M. Reddy, A. K. Chopra, and S. K. Srivastava, "Aldose reductase mediates the lipopolysaccharide-induced release of inflammatory mediators in RAW264.7 murine macrophages," Journal of Biological Chemistry, vol. 281, no. 44, pp. 33019-33029, 2006.

[30] J.-M. Zhang and J. An, "Cytokines, inflammation, and pain," International Anesthesiology Clinics, vol. 45, no. 2, pp. 27-37, 2007.

[31] L. W. Soromou, Z. Zhang, R. Li et al., "Regulation of inflammatory cytokines in lipopolysaccharide-stimulated RAW 264.7 murine macrophage by 7-O-methyl-naringenin," Molecules, vol. 17, no. 3, pp. 3574-3585, 2012.

[32] N. Parameswaran and S. Patial, "Tumor necrosis factor- $\alpha$ signaling in macrophages," Critical Reviews in Eukaryotic Gene Expression, vol. 20, no. 2, pp. 87-103, 2010.

[33] A. Rubini, "Interleukin-6 and lung inflammation: evidence for a causative role in inducing respiratory system resistance increments," Inflammation and Allergy-Drug Targets, vol. 12, no. 5, pp. 315-321, 2013.

[34] M. Akdis, S. Burgler, R. Crameri et al., "Interleukins, from 1 to 37 , and interferon- $\gamma$ : receptors, functions, and roles in diseases," Journal of Allergy and Clinical Immunology, vol. 127, no. 3, pp. 701-721, 2011.

[35] H. Mühl and J. Pfeilschifter, "Anti-inflammatory properties of pro-inflammatory interferon- $\gamma$," International Immunopharmacology, vol. 3, no. 9, pp. 1247-1255, 2003.

[36] M. B. Everhart, W. Han, T. P. Sherrill et al., "Duration and intensity of NF- $\kappa \mathrm{B}$ activity determine the severity of endotoxin-induced acute lung injury," The Journal of Immunology, vol. 176, no. 8, pp. 4995-5005, 2006.

[37] B. Kaminska, "MAPK signalling pathways as molecular targets for anti-inflammatory therapy--from molecular mechanisms to therapeutic benefits," Biochimica et Biophysica Acta, vol. 1754, no. 1-2, pp. 253-262, 2005.

[38] S. Liu, G. Feng, G.-l. Wang, and G.-j. Liu, "p38MAPK inhibition attenuates LPS-induced acute lung injury involvement of NF- $\kappa$ B pathway," European Journal of Pharmacology, vol. 584, no. 1, pp. 159-165, 2008.

[39] P. Moine, R. McIntyre, M. D. Schwartz et al., "NF- $\kappa$ B regulatory mechanisms IN alveolar macrophages from patients with acute respiratory distress syndrome," Shock, vol. 13, no. 2, pp. 85-91, 2000.

[40] K. Schulze-Osthoff, D. Ferrari, K. Riehemann, and S. Wesselborg, "Regulation of NF-kappa B activation by MAP kinase cascades," Immunobiology, vol. 198, no. 1-3, pp. 35-49, 1997.

[41] M. Karin, "How NF- $\kappa$ B is activated: the role of the $\mathrm{I} \kappa \mathrm{B}$ kinase (IKK) complex," Oncogene, vol. 18, no. 49, pp. 6867-6874, 1999.

[42] W. Zhong, Y. Cui, Q. Yu et al., "Modulation of LPS-stimulated pulmonary inflammation by Borneol in murine acute lung injury model," Inflammation, vol. 37, no. 4, pp. 1148-1157, 2014.

[43] P. Sun, K. Zhou, S. Wang et al., "Involvement of MAPK/NFkappaB signaling in the activation of the cholinergic antiinflammatory pathway in experimental colitis by chronic vagus nerve stimulation," PLoS One, vol. 8, no. 8, Article ID e69424, 2013. 